\title{
Ahmed Hassan Zewail
}

$$
\text { (1946-2016) }
$$

\section{Nobel-winning inventor of femtochemistry and statesman.}

\section{$\mathrm{T}$} hat the first science Nobel prizewinner from the Arabic-speaking world, Ahmed Hassan Zewail, pioneer of ultrafast chemistry, was also a diplomat is apparent in his unique list of distinctions. Few scientists can have been garlanded by foundations in both Israel and Saudi Arabia, served in the Pontifical Academy of Sciences - and had their face on several postage stamps while living. He died on 2 August 2016, aged 70 .

The eldest child of a middleclass family, Zewail was born on 26 February 1946. He grew up 덨 in Desouk, Egypt, a small town 80 kilometres from Alexandria. After a state-school education, he took undergraduate and masters degrees in chemistry at the University of Alexandria. He then decided to further his studies in the United States, despite a fairly weak command of English (a fact which shocks those of us who knew this eloquent speaker later on).

He did his graduate work on novel spectroscopies, including optically detected magnetic resonance, with Robin Hochstrasser at the University of Pennsylvania in Philadelphia. His postdoctoral work was on coherence in multidimensional systems and energy transfer in solids, with Charles B. Harris at the University of California, Berkeley. In 1976 he joined the California Institute of Technology in Pasadena, where he remained for the rest of his career, rising to become the Linus Pauling professor of chemistry in 1995. Like Pauling, his reputation and impact would truly transcend science.

Throughout the 1980s and most of the 1990s he led his group to do experiments on 'femtochemistry' - his coinage for causing and watching reactions using light pulses lasting much less than a picosecond (a millionth of a millionth of a second). This is the timescale of chemical reactions at the molecular level - the timescale of vibrations and nuclear motions. For this work he became the sole recipient of the 1999 Nobel Prize in Chemistry. Before the advent of such ultrafast lasers in the 1970s, chemists' ideas of the dynamics of molecules in excited states were very different from todays.' They believed

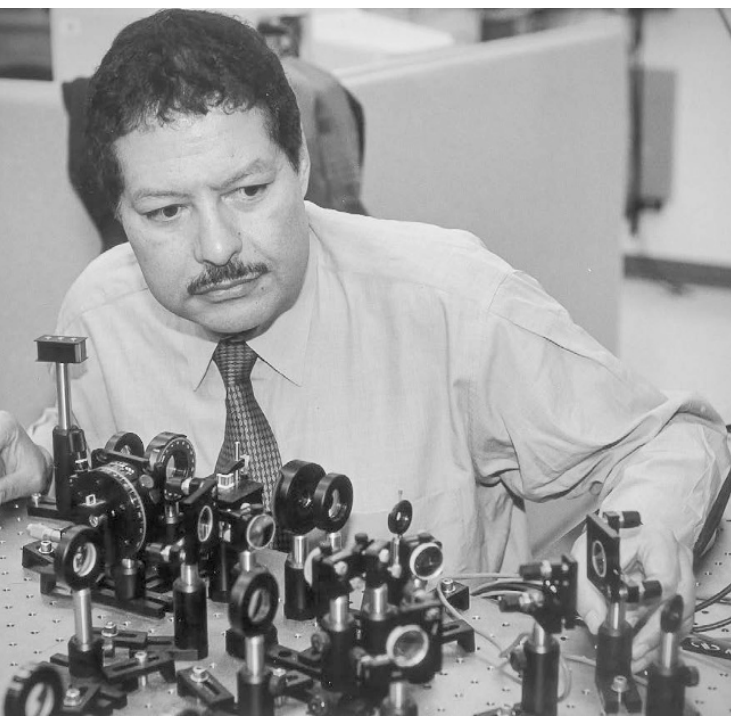

the view that science transcends political borders. One early incident illustrates this. In January 1983, he organized the International Conference on Photochemistry and Photobiology at his alma mater in Alexandria. He was clearly a rising star, but the work that would lead to the Nobel had barely started. The conference was a major milestone in his career, attracting a stunning collection of distinguished international scientists, with an obvious subtext of bootstrapping progress for Egyptian science in general.

Given the tumultuous politics of the region then, as now, it was no surprise that as soon as Israeli scientists arrived, most of the Arab representatives were ordered that the dominant force was intramolecular relaxation, and that this was largely incoherent.

Zewail's work shattered this picture. Through elegant experiments, his group unravelled reaction dynamics, clarified molecular pathways and illuminated the quantum-mechanical evolution of atoms in molecules. The classic tool for him was the pump-probe experiment. Here the first pulse (the pump) started a chemical reaction, and the second (the probe) monitored what happened next. In this way he and his team took snapshots of vibrational flow, state rearrangement and reaction products. These revealed a much deeper role for coherence than anyone had anticipated.

After his Nobel Prize, Zewail's focus shifted towards a new form of microscopy that used ultrafast pulses of electrons to track reactions in space and time at the atomic scale. It was no secret that he hoped (like Pauling) to win a second Nobel Prize: Zewail was not one to rest on his laurels. Once again, truly elegant science resulted.

Generations of talented students benefited greatly from his insight. He longed to boil down complex phenomena to the simplest underlying dynamics. He would urge his coworkers to avoid getting mired in detail. A very, very busy man, he still kept close tabs on his sub-basement labs. He would pop in during an experiment without warning, poke around, and start asking questions, saying he just wanted to "smell the cooking".

His career and influence were shaped by by their governments to leave. Zewail surely would have expected this and could have taken the easy way out - asking his Israeli friends (who were numerous) to stay away. Instead he publicly denounced at the conference the destructive acts of the same governments he was trying to help guide to modernity.

Zewail never lost his drive to modernize science in the Arabic-speaking world. In speeches and articles he reminded his countrymen of the historical greatness of their science, and encouraged them to build to greatness again through investment in education and fundamental research. He was the driving force behind the Zewail City of Science and Technology in October City, Giza. After a troubled gestation due to political instability, this new university finally opened in 2013, with institutes intended to cover all the fields required for development of Egyptian society. Zewail was also on US president Barack Obama's Council of Advisors on Science and Technology for four years and served as the US science envoy to the Middle East.

With his death, we have lost a talented scientist and true statesman of the world.

Warren S. Warren is the chair of the Physics Department at Duke University, and James B. Duke Professor of Chemistry, Physics, Radiology and Biomedical Engineering. He was a postdoctoral fellow with Zewail from 1981 to 1982.

e-mail:warren.warren@duke.edu 